in vivo $33: 297-302(2019)$

doi:10.21873/invivo.11475

Review

\title{
The Role of 3D Printing in Colorectal Surgery: Current Evidence and Future Perspectives
}

\author{
XENOFON PAPAZARKADAS ${ }^{1,2}$, ELEFTHERIOS SPARTALIS ${ }^{1,2}$, DIMITRIOS PATSOURAS ${ }^{1,2}$, \\ ARGYRIOS IOANNIDIS ${ }^{1}$, DIMITRIOS SCHIZAS ${ }^{2,3}$, KONSTANTINOS GEORGIOU $^{1}$, \\ DIMITRIOS DIMITROULIS ${ }^{2,4}$ and NIKOLAOS NIKITEAS ${ }^{1,2,4}$ \\ ${ }^{1}$ Laboratory of Experimental Surgery and Surgical Research, University of Athens Medical School, Athens, Greece; \\ ${ }^{2}$ Hellenic Minimally Invasive and Robotic Surgery (MIRS) Study Group, Athens, Greece; \\ ${ }^{3}$ First Department of Surgery, National and Kapodistrian University of Athens Medical School, Athens, Greece; \\ ${ }^{4}$ Second Department of Propaedeutic Surgery, \\ National and Kapodistrian University of Athens Medical School, Athens, Greece
}

\begin{abstract}
Background: Three-dimensional (3D) printing is an emerging and evolving technology with a variety of possible applications in surgery. The purpose of this study was to examine its potential applications in the field of colorectal surgery, as a tool in pre-operative planning and peri-operative navigation, as well as in training. Its costefficiency was also examined. Materials and Methods: A literature review was conducted on articles specifically presenting various applications of $3 D$ printing in the field of colorectal surgery. PubMed was the primary database researched. Results: A total of seven studies were found to meet the inclusion criteria. The majority of the articles employed $3 D$ printing technology to produce patient-specific anatomic replicas to enhance pre-operative planning, providing satisfactory results. One study used $3 D$ printing technology as a therapy tool, stating superior results over traditional methods. Conclusion: $3 D$ printing is a novel technology with a broad spectrum of possible applications in colorectal surgery. Anatomic replicas specific to the anatomy of a patient with acceptable dimensional correlations can be produced using the currently available technology. Surgical and patient training can also be enhanced. Depending on the technology used, costs greatly vary and can thus hinder popularization of this technology in surgery.
\end{abstract}

This article is freely accessible online.

Correspondence to: Eleftherios Spartalis, MD, M.Sc, Ph.D., FACS, 49 Vasilissis Sofias Ave. Athens, 10676, Greece. Mobile: +30 6974714078, e-mail: Eleftherios.spartalis@gmail.com

Key Words: 3D printing, image-guided surgery, colorectal surgery.
Three-dimensional (3D) printing describes a diverse array of technologies employed for the production of a 3D object layer by layer, via the accumulation or fusion of each respective material. Initially developed in the early 1980s (1), the concept of 3D printing has evolved well over the past decades, transforming into an attractive method of rapid manufacturing, while discovering plenty of commercial applications, including in the field of medicine. Either via the production of objects directly used in patients, such as personalized prostheses (2), or as an adjunct to current imaging techniques used by medical staff to enhance the quality of their work (3), 3D printing is becoming more and more popular among various disciplines of medicine, especially surgery $(4,5)$. Research on its applications appears to have mainly been aimed towards maxillofacial and orthopaedic operations $(6,7)$, due to the more efficient imaging of bone structures, as well as due to the advent of materials that can be sterilized (7). Despite that, the process of 3D printing could be implemented in other surgical specialties, offering new ways to optimize surgical approach towards certain types of procedures.

Technology behind $3 D$ printing. The process of the production of an object, be it either a tool or an anatomic replica for a patient, includes a series of steps that make up the transition from a 2D digital image to a 3D object. In each step, different types of software are utilized (Figure 1).

To produce a tailored anatomic replica based on a specific patient, images of the patient's anatomy must first be obtained. Although multiple non-invasive image acquiring techniques such as magnetic resonance imaging, ultrasonography or positron-emission tomography can be used, multiple detector computed tomography seems to be employed usually because image post-processing for this is less complex (8). 


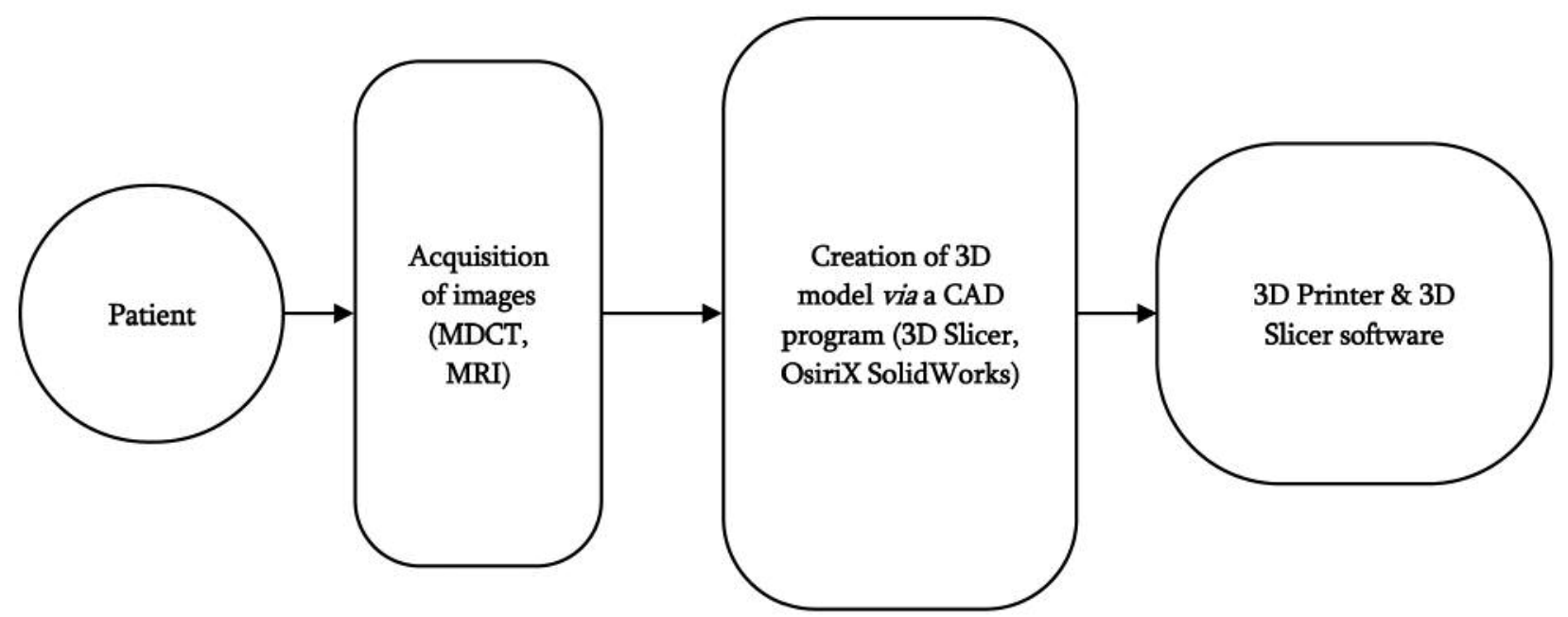

Figure 1. Types of software utilized in three-dimensional (3D) printing. MDCT: Multi-detector computed tomography, MRI: magnetic resonance imaging, CAD: computed-aided design.

The next step is to produce a digital 3D model of the acquired images through a computer-aided design (CAD) program. In turn, the $\mathrm{CAD}$ file is converted to a format that can be utilized for 3D printing. The STL format is the golden standard for data transfer between the CAD software and a 3D printer (1).

Types of $3 D$ printing technologies. There are many distinct 3D printing technologies to choose among, each with different advantages and disadvantages (9).

Stereolithography (SLA): SLA is the earliest 3D printing method described and the most popular one. UV light is employed to solidify a liquid photoactive resin via polymerization, building an object layer by layer (1). The produced object then needs to be manually edited and cured in a UV chamber (10). Although a rather expensive and laborintensive option, SLA offers impressive object resolution, ideal for the production of hollow objects (e.g. vascular models) and offers the option of using biocompatible materials $(10,11)$. One restriction to be considered is that only one type of material can be used per printed item.

Fuel deposition modelling (FDM): FDM is a common and relatively cheap $3 \mathrm{D}$ printing method that uses heat to create an object layer by layer from melted plastic (12). Although its low cost and the benefit of using multiple materials make FDM an attractive 3D printing method, the slow printing time and the potentially lower resolution than other methods are noteworthy disadvantages (11).

MultiJet modelling (MJM): MJM is a process similar to SLA, with the difference that the time-consuming post prototyping process where the object is cured by UV light happens immediately after its production (10). MJM offers high resolution and the option of using multiple materials, making it a viable choice for colored coded objects. Its high cost is a restraining factor.

Objective. The objective of this article was to review the contemporary literature regarding the application of $3 \mathrm{D}$ printing in the field of colorectal surgery and its efficacy in regard to its costs. Aspects such as surgical training, preoperation strategy planning, synthesis of implants, as well as patient training are examined.

\section{Materials and Methods}

The Preferred Reporting Items for Systematic Reviews and MetaAnalyses (PRISMA) guidelines were used for the purpose of this systematic review (13). A study protocol was initially established for the identification of articles.

Literature search. MEDLINE/PubMed was the primary database used for the purpose of this research. Additional sources (e.g. ResearchGate) were used to yield more results. Terms pertinent to the subject of the application of $3 \mathrm{D}$ printing in colorectal surgery were used (e.g. 3D printed colorectal surgery, 3D printed rectal surgery, rapid prototyping in gastrointestinal surgery, etc.) as well as abbreviations, synonyms and potentially alternative spelling motifs. MeSH terms were employed to increase yield inclusion. The final search was performed on 14th September 2018.

Inclusion criteria: Full-text studies discussing the application of 3D printing in the field of colorectal surgery, in pre-operative strategy planning, surgical training, patient training or material production were included.

Exclusion criteria: Non-English studies, studies in paediatric populations, studies concerning operations for causes secondary to gastrointestinal tract diseases (i.e. liver metastases in colorectal cancer). 
Table I. Studies included in the systematic review.

\begin{tabular}{|c|c|c|c|}
\hline Study (Ref) & Type of study & Year & Description of study \\
\hline Luzon et al. (15) & Prospective multicenter trial & 2018 & $\begin{array}{c}\text { Implementation of 3D printed superior mesenteric vascular models } \\
\text { for surgical planning and/or navigation in right colectomy with extended } \\
\text { D3 mesenterectomy: Comparison of virtual and physical models } \\
\text { to the anatomy found at surgery. }\end{array}$ \\
\hline Bageas et al. (14) & Randomised controlled trial & 2018 & Three-dimensional printing as an educational tool in colorectal surgery. \\
\hline Huang et al. (19) & Case report & 2017 & $\begin{array}{l}\text { 3D-printed "fistula stent" designed for management of enterocutaneous fistula: } \\
\text { An advanced strategy. }\end{array}$ \\
\hline Tominaga et al. (21) & Case report & 2016 & $\begin{array}{l}\text { Usefulness of three-dimensional printing models } \\
\text { for patients with stoma construction. }\end{array}$ \\
\hline Sahnan et al. (18) & Technical note & 2018 & $\begin{array}{l}\text { Innovation in the imaging perianal fistula: } \\
\text { A step towards personalised medicine. }\end{array}$ \\
\hline Hamabe and Ito (17) & Technical note & 2017 & $\begin{array}{l}\text { A three-dimensional pelvic model made with a three-dimensional printer: } \\
\text { Applications for laparoscopic surgery to treat rectal cancer. }\end{array}$ \\
\hline Garcia-Granero et al. (16) & Technical note & 2017 & $\begin{array}{l}\text { Application of three-dimensional printing in laparoscopic dissection to } \\
\text { facilitate D3-lymphadenectomy for right colon cancer. }\end{array}$ \\
\hline
\end{tabular}

Data extraction. The initial search yielded 38 articles. Duplicate removal resulted in a reduction of 15 studies. Further elimination of 14 records followed via screening of titles and abstracts. A pool of nine full-text articles were examined. Certain articles were characterized as thematically irrelevant and were excluded. The final study pool included seven articles (Table I).

Characteristics of included studies: One randomized controlled trial, two case series, three case reports and one technical note were included. The search and elimination process of the study is presented in a flow chart (Figure 2).

\section{Results}

Preoperative planning. One article described a randomized controlled trial where 3D anatomic replicas of patients with anorectal fistulas were produced and assessed by sixth year resident surgeons, resulting in higher overall scores in fistula assessment tests and better scores in preoperative planning. Participants of the group that utilized the 3D models stressed that they improved their preoperative awareness and noted the value of 3D models in surgical training (14).

Another study produced superior mesenteric vascular models of 22 patients and compared the accuracy of visual and physical models in regard to patient anatomy, assessing their value in surgical planning and navigation in right hemicolectomy with extended D3 mesenterectomy (15). Results showed acceptable dimensional correlations among 3D printed models, visual STL models and operational tissue anatomy of the mesenteric vessels. The weakest correlations were found for intra-venous distances between 3D models and perioperational measurements, due to the unique physiological and volumetric traits of veins regarding dilatability and volume changing. However, the study concluded that 3D printed models are promising as adjuncts to preoperative planning and as a tool for peri-operative navigation.
Garcia-Granero et al. produced a 3D model to examine the vascular anatomy of a patient with right colon cancer and planned a laparoscopic right hemicolectomy with complete mesocolic excision and high tie ligation of ileocolic, right colic and right branch of the middle colic vessels with dissection of gastrocolic trunk of Henle and surgical trunk of Gillot and high tie of the superior right colic vein (16). In order to facilitate navigation among vessels with high variance in the area of the gastrocolic trunk of Henle and the surgical trunk of Gillot, they produced a personalized 3D model of their patient's anatomy. Observations on the efficacy of their endeavour were not mentioned.

More studies appear to have successfully created anatomic replicas that correlated well to the anatomy of the patients. Hamabe and Ito created two 3D pelvic models, one of a healthy male and one of a female patient with rectal cancer (17). These models facilitated the observation of deeper anatomic structures of the pelvis.

Sahnan et al. examined the efficacy of producing 3D models of complex perianal fistulas, stressing that although $3 \mathrm{D}$ reproduction of patient images offers no new information to the 2D images, they can improve conceptualization, providing a more realistic representation of anatomy, aiding clinical communication and surgical planning (18).

Finally, in one study, a stent with tailor-made proportions was created specifically for a patient with an enterocutaneous fistula, providing superior results to traditional plugging techniques (19).

Training the surgeon and the patient. Although the benefits of the applications of 3D printing technology in surgical training are established [reviewed in (20)], there are not enough data in the literature to provide a solid conclusion as 


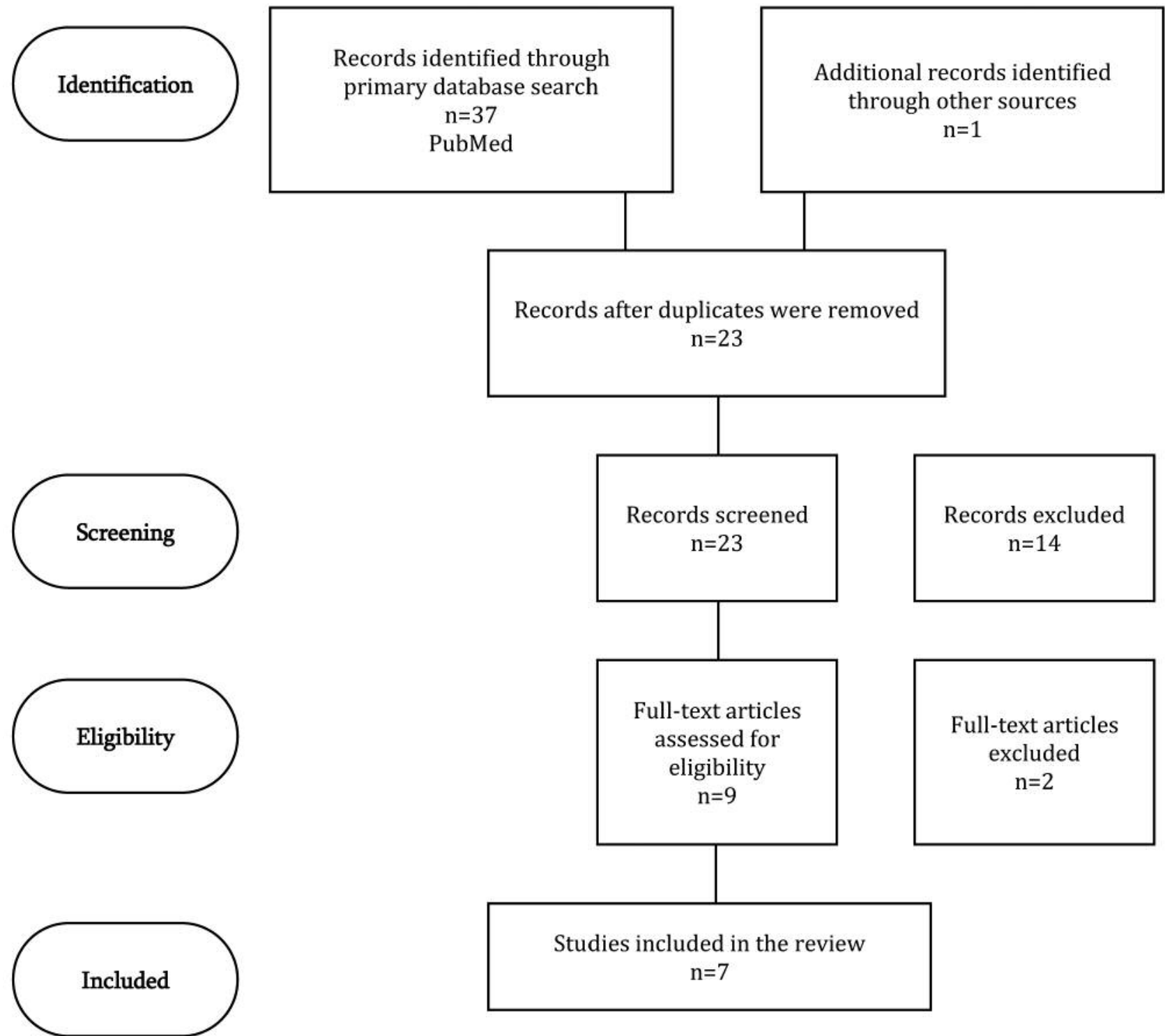

Figure 2. PRISMA flow diagram.

to the benefits of 3D printing applications specifically in the field of colorectal surgery.

Bageas et al. noted that touching, manipulating and exploring the patient's pathology on the 3D model improved the quality of training offered to resident surgeons, enhancing surgical skills (14).

Sahnan et al. mentioned that benefits of 3D printing to more experienced surgeons could be more difficult to ascertain, but could be more beneficial to those with less experience (18). Indeed, articles providing sufficient and thorough data to reach a well-documented conclusion are scarce. Thus, more similarly planned studies aiming to investigate the role of $3 \mathrm{D}$ printing in colorectal surgeon training need to be produced in order for more sufficient data to be available.

Apart from surgical training, 3D printing technology can also be employed to enhance patient training. Tominaga et al. used 3D printing technology to create patient-specific stoma models prior to surgery (21). The group created a new tool for patient training, improving patients' understanding of daily stoma care and reducing the time needed for the acquisition of this new skill, potentially reducing future stoma-related complications such as peristoma skin lesions. 
Table II. Types of hardware, software and cost of each study.

\begin{tabular}{|c|c|c|c|c|c|c|}
\hline Study (Ref) & $\begin{array}{l}\text { Type of 3D } \\
\text { printer }\end{array}$ & $\begin{array}{l}\text { 3D Printer } \\
\text { cost }\end{array}$ & $\begin{array}{c}\text { CAD } \\
\text { Software }\end{array}$ & $\begin{array}{l}\text { Imaging } \\
\text { technique }\end{array}$ & $\begin{array}{c}\text { Cost } \\
\text { per item }\end{array}$ & $\begin{array}{l}\text { Materials } \\
\text { used }\end{array}$ \\
\hline Luzon et al. (15) & SLA $($ Form +1$)$ & $3000 \$$ & $\begin{array}{c}\text {-OsiriX } \\
\text {-Mimics medical imagine } \\
\text { processing software } \\
\text {-3-Matic Medical software }\end{array}$ & MDCTA & $21-34 \$$ & $\begin{array}{c}\text { A mixture of methacrylates } \\
\text { photo activators, pigments } \\
\text { and additives. }\end{array}$ \\
\hline Bageas et al. (14) & FDM (MakerBot) & $€ 2500$ & Google SketchUp & MRI & $€ 3$ & Polylactic acid \\
\hline Huang et al. (19) & FDM & N/D & SolidWork & HRCT & $\mathrm{N} / \mathrm{D}$ & Thermoplastic urethane \\
\hline Tominaga et al. (21) & $\begin{array}{l}\text { SLA (Objet } 260 \\
\quad \text { Connex) }\end{array}$ & $\mathrm{N} / \mathrm{D}$ & $\begin{array}{l}\text { Geomagic } \\
\text { Free Form }\end{array}$ & $\begin{array}{l}\text { Artec 3D } \\
\text { scanner }\end{array}$ & $100 \$$ & N/D \\
\hline Sahnan et al. (18) & $\begin{array}{l}\text { FDM (Ultimaker } \\
3 \text { Extended) }\end{array}$ & $\mathrm{N} / \mathrm{D}$ & $\begin{array}{c}\text {-Cura (Ultimaker Cura 3.0.4) } \\
\text {-Touch Surgery }\end{array}$ & MRI & $\mathrm{N} / \mathrm{D}$ & $\mathrm{N} / \mathrm{D}$ \\
\hline Hamabe and Ito (17) & $\begin{array}{l}\text { MJM (Objet500 } \\
\text { Connex3) }\end{array}$ & $\mathrm{N} / \mathrm{D}$ & $\begin{array}{c}\text {-ZedView } \\
\text {-Geomagic Freeform }\end{array}$ & MDCT & $2250 \$$ & UV resin (not specified) \\
\hline $\begin{array}{l}\text { Garcia-Granero } \\
\text { et al. (16) }\end{array}$ & SLA & $\mathrm{N} / \mathrm{D}$ & $\mathrm{N} / \mathrm{D}$ & MDCT & $\mathrm{N} / \mathrm{D}$ & $\begin{array}{l}\text { Acrylonitrile butadiene } \\
\text { styrene (vessels), } \\
\text { transparent polyurethane } \\
\text { rubber (hollow viscus) }\end{array}$ \\
\hline
\end{tabular}

3D: Three-dimensional; CAD: computer-aided design; SLA: stereolithography; MDCTA: multi-detector computed tomographic angiography; FDM: fused deposition modelling; MRI: magnetic resonance imaging; HRCT: high resolution computed tomography; MJM: MultiJet printing; UV: ultra violet; N/D: not disclosed.

Material use and costs. Multiple 3D printing techniques are available, providing variable results and costs. Criteria to determine the choice of each technique include cost, type of tissue (vessels, muscles, hollow viscus, et cetera), and production time for available models (10). It should be noted that cost naturally appears as a barrier. In our research, costs greatly varied mainly based on the selection of materials used for 3D printing. Another matter to be considered is the software needed for the transition from $2 \mathrm{D}$ images to a $3 \mathrm{D}$ digital model. While there is a vast array of available software, both free and paid, choice of software is a factor that could potentially increase costs. Further editing is also possible, requiring extra pieces of software. Even after its production, the physical 3D model can be further adjusted in order to enhance the final product (15).

Finally, the implementation of the product comes into play. On one hand, the production of anatomic replicas requires choosing materials based on the focused anatomic region. On the other hand, production of protheses such as stents requires that the materials used for the production of the final product should be sterilizable (19). Table II presents the types of hardware, software and materials used in each retrieved study, as well as the approximate cost per unit produced.

\section{Discussion}

Contemporary literature shows evidence that the production of personalized models based on the anatomy of the patient can be utilized as adjuncts to the operational planning, even as navigational tools peri-operatively. Furthermore, the role of 3D models in surgical training also appears promising, especially regarding complicated pathologies such as perianal fistula. Finally, patient training is another area where the scant data available show the potential benefits of the implementation of 3D printing.

Undoubtedly there are obstacles to be overcome. The popularization of $3 \mathrm{D}$ printing in the surgical field requires the possession of specific software and hardware, that in turn require further funds for upgrades and maintenance. Use of these tools requires further training of medical staff, which could prove a difficult task to achieve.

Current implementation of $3 \mathrm{D}$ printing in the field of colorectal surgery, although promising, leaves a lot to be desired.

Future research is necessary to further examine the role of $3 \mathrm{D}$ printing in the holistic approach of the surgical patient, as well as its efficiency regarding its cost.

\section{Conclusion}

3D printing appears to be beneficial in better understanding the spatial relationships in complicated anatomical regions such the pelvis or vascular regions of the abdomen. This novel technology can be employed for surgical training as well as pre-operative planning and peri-operative navigation.

\section{Limitations}

Due to the specific nature of the subject and the recent implementation of $3 \mathrm{D}$ printing technology in surgical planning in 
colorectal surgery, ample data were not available for research. Thus, this study included case reports and technical notes. No articles of secondary nature were included. It is possible therefore that through the inclusion of certain studies some bias was introduced

\section{Funding}

This study had no funding.

\section{Conflicts of Interest}

No conflicts of interest or financial relationships exist to be disclosed.

\section{References}

1 Gross BC, Erkal JL, Lockwood SY, Chen C and Spence DM: Evaluation of $3 \mathrm{D}$ printing and its potential impact on biotechnology and the chemical sciences. Anal Chem 86(7): 3240-3253, 2014.

2 Leukers B, Gulkan H, Irsen SH, Milz S, Tille C, Schieker M and Seitz H: Hydroxyapatite scaffolds for bone tissue engineering made by 3D printing. J Mater Sci: Mater Med 16(12): 11211124, 2005.

3 Fasel JH, Aguiar D, Kiss-Bodolay D, Montet X, Kalangos A, Stimec BV and Ratib O: Adapting anatomy teaching to surgical trends: A combination of classical dissection, medical imaging, and 3D-printing technologies. Surg Radiol Anat 38(3): 361-367, 2016.

4 Malik HH, Darwood AR, Shaunak S, Kulatilake P, El-Hilly AA, Mulki $O$ and Baskaradas A: Three-dimensional printing in surgery: A review of current surgical applications. J Surg Res 199(2): 512-522, 2015.

5 Witowski JS, Coles-Black J, Zuzak TZ, Pedziwiatr M, Chuen J, Major $\mathrm{P}$ and Budzynski A: 3D printing in liver surgery: A systematic review. Telemed J E Health 23(12): 943-947, 2017.

6 Martelli N, Serrano C, van den Brink H, Pineau J, Prognon P, Borget I and El Batti S: Advantages and disadvantages of 3dimensional printing in surgery: A systematic review. Surgery 159(6): 1485-1500, 2016.

7 Auricchio F and Marconi S: 3D printing: Clinical applications in orthopaedics and traumatology. EFORT Open Rev 1(5): 121127,2016

8 Rengier F, Mehndiratta A, von Tengg-Kobligk H, Zechmann CM, Unterhinninghofen R, Kauczor HU and Giesel FL: 3D printing based on imaging data: review of medical applications. Int J Comput Assist Radiol Surg 5(4): 335-341, 2010.

9 Jianbin $X$ and Jasveer S: Comparison of different types of 3D printing technologies. Int $\mathrm{J}$ Sci Res Publ 8(4): doi: 10.29322/IJSRP.8.4.2018.p7602, 2018

10 Chae MP, Rozen WM, McMenamin PG, Findlay MW, Spychal RT and Hunter-Smith DJ: Emerging applications of bedside 3D printing in plastic surgery. Front Surg 2: 25, 2015.

11 George E, Liacouras P, Rybicki FJ and Mitsouras D: Measuring and establishing the accuracy and reproducibility of 3D printed medical models. Radiographics 37(5): 1424-1450, 2017.

12 Ventola CL: Medical applications for 3D printing: Current and projected uses. P T 39(10): 704-711, 2014.
13 Moher D, Liberati A, Tetzlaff J, Altman DG, Antes G, Atkins D, Barbour V, Barrowman N, Berlin JA, Clark J, Clarke M, Cook D, D'Amico R, Deeks J, Devereaux PJ, Dickersin K, Egger M, Ernt E, Gotzsche PC, Grimshaw J, Guyatt G, Higgins J, Ioannidis JP, Kleijnen J, Lang T, Magrini N, McNamee D, Moja L, Mulrow C, Napoli M, Oxman A, Pham B, Rennie D, Sampson M, Schulz KF, Shekelle PG, Tetzlaff J, Tovey D and Tuwell P: Preferred reporting items for systematic reviews and meta-analyses: The PRISMA statement. Int J Surg 8(5): 336-341, 2010.

14 Bangeas P, Drevelegas K, Agorastou C, Tzounis L, Chorti A, Paramythiotis D, Michalopoulos A, Tsoulfas G, Papadopoulos V, Exadaktylos A and Suri J: Three-dimensional printing as an educational tool in colorectal surgery. Front Biosci doi: 10.2741/13487, 2018

15 Luzon JA, Andersen BT, Stimec BV, Fasel JHD, Bakka AO, Kazaryan AM and Ignjatovic D: Implementation of 3D printed superior mesenteric vascular models for surgical planning and/or navigation in right colectomy with extended D3 mesenterectomy: Comparison of virtual and physical models to the anatomy found at surgery. Surg Endosc doi:10.1007/s00464018-6332-8, 2018.

16 Garcia-Granero A, Sanchez-Guillen L, Fletcher-Sanfeliu D, FlorLorente B, Frasson M, Sancho Muriel J, Alvarez Serrado E, Pellino G, Grifo Albalat I, Giner F, Roca Estelles MJ, Esclapez Valero $\mathrm{P}$ and Garcia-Granero E: Application of threedimensional printing in laparoscopic dissection to facilitate D3lymphadenectomy for right colon cancer. Tech Coloproctol 22(2): 129-133, 2018.

17 Hamabe A and Ito M: A three-dimensional pelvic model made with a three-dimensional printer: Applications for laparoscopic surgery to treat rectal cancer. Tech Coloproctol 21(5): 383-387, 2017.

18 Sahnan K, Adegbola SO, Tozer PJ, Patel U, Ilangovan R, Warusavitarne J, Faiz OD, Hart AL, Phillips RKS and Lung PFC: Innovation in the imaging perianal fistula: A step towards personalised medicine. Therap Adv Gastroenterol 11: doi: 10.1177/1756284818775060, 2018.

19 Huang JJ, Ren JA, Wang GF, Li ZA, Wu XW, Ren HJ and Liu S: 3D-printed "fistula stent" designed for management of enterocutaneous fistula: An advanced strategy. World J Gastroenterol 23(41): 7489-7494, 2017.

20 Langridge B, Momin S, Coumbe B, Woin E, Griffin M and Butler P: Systematic review of the use of 3-dimensional printing in surgical teaching and assessment. J Surg Educ 75(1): 209-221, 2018.

21 Tominaga T, Takagi K, Takeshita H, Miyamoto T, Shimoda K, Matsuo A, Matsumoto K, Hidaka S, Yamasaki N, Sawai T and Nagayasu T: Usefulness of three-dimensional printing models for patients with stoma construction. Case Rep Gastroenterol 10(1): 57-62, 2016. 